\title{
LYRIC VÍDEOS: EL ENCUENTRO DEL VIDEOCLIP CON EL DISEÑO GRÁFICO Y LA COMPOSICIÓN TIPOGRÁFICA
}

\section{Lyric videos: the meeting of the music video with graphic design and the typographic composition.}

José Patricio Pérez Rufí: Universidad de Málaga. España.

patricioperez@uma.es

\section{RESUMEN}

Este artículo tiene por objeto principal el análisis del lyric vídeo a fin de definir el formato como creación audiovisual comercial, describir el uso de los recursos formales relacionados con el uso del texto $\mathrm{y}$, en un segundo paso, realizar una clasificación de los lyric vídeos en función de las variables consideradas en la metodología de análisis. El lyric vídeo es un subgénero dentro del vídeo musical que representa a través de códigos textuales íntegramente el contenido verbal de una canción, por lo general de manera sincronizada con aquella. Incluso como un formato de producción muy económica en cuanto a presupuestos, el lyric vídeo se ha convertido en un fenómeno popular gracias a su distribución a través de YouTube y otras plataformas de vídeo online. Para lograr los objetivos propuestos, realizaremos un análisis de contenido en una muestra de lyric videos, a partir de una metodología basada en las propuestas de diversos autores que atienda a la relación del discurso audiovisual con los códigos textuales y el diseño gráfico. Los resultados a los que llevan nuestro análisis destacan la naturaleza gráfica y digital del formato, en el que raramente se utiliza como recurso formal la imagen fílmica grabada de forma previa a la edición. De igual modo, los textos escritos aparecerían integrados en el discurso de manera extradiegética y alternaría diversas fuentes tipográficas, por lo general en movimiento, con objeto de lograr un alto dinamismo y así seducir al espectador.

\section{PALABRAS CLAVE}

Vídeo musical; Lyric vídeo; Diseño gráfico; Análisis del discurso audiovisual; Tipografía cinética; YouTube; Fandom

\begin{abstract}
The main purpose of this article is the analysis of the lyric video in order to define the format as a commercial audiovisual creation, to describe the use of formal resources related to the use of the text and, in a second step, to make a classification of the lyric videos in function of the variables considered in the analysis methodology. The lyric video is a subgenre within the music video that represents, through textual codes, the entire verbal content of a song, usually synchronized with that one. Even as a very economical production format in terms of budgets, lyric video has become a popular phenomenon thanks to its distribution through YouTube and other online video
\end{abstract}


platforms. To achieve the proposed objectives, we will conduct a content analysis in a sample of lyric videos, based on a methodology based on the proposals of various authors that address the relationship of audiovisual discourse with textual codes and graphic design. The results of our analysis highlight the graphic and digital nature of the format, in which the recorded film image is rarely used as a formal resource prior to editing. In the same way, the written texts would appear integrated in the discourse in an extradiegetic way and would alternate various typographical sources, usually in movement, in order to achieve a high dynamism and thus seduce the viewer.

\section{KEY WORDS}

Music Video; Lyric Video; Graphic Design; Audio-visual text analysis; Kinetic Typography; YouTube; Fandom

\section{LYRIC VÍDEOS: O ENCONTRO DO VIDEOCLIPE COM O DESENHO GRÁFICO E A COMPOSIÇÃO TIPOGRÁFICA}

\section{RESUME}

Este artigo tem como objetivo principal a analises do lyric vídeo afim de definir o formato como criação audiovisual comercial, descrever o uso dos recursos formais relacionados com o uso do texto e, em segundo passo, realizar uma classificação dos lyric vídeos em função das variáveis consideradas na metodologia de analises. $\mathrm{O}$ lyric vídeo é um subgênero dentro do vídeo musical que representa através de códigos textuais integramente o conteúdo verbal de uma canção, geralmente de maneira sincronizada com aquela. Incluso como um formato de produção muito econômica enquanto pressupostos, o lyric vídeo se converteu em um fenômeno popular graças a sua distribuição através de Youtube e outras plataformas de vídeo online. Para lograr os objetivos propostos, realizaremos uma analises de conteúdo em uma amostra de lyric vídeos, a partir de uma metodologia baseada em propostas de diversos autores que atenda a relação do discurso audiovisual com os códigos textuais e o desenho gráfico. Os resultados que revelam nossas analises destacam a natureza gráfica e digital do formato, no qual raramente se utiliza como recurso formal a imagem fílmica gravada de forma previa a edição. De igual modo, os textos escritos apareceriam integrados no discurso de maneira extra diegético e alternaria diversas fontes tipográficas, em geral em movimento, com objetivo de lograr um auto dinamismo e assim seduzir ao expectador.

\section{PALAVRAS CHAVE}

Vídeo musical; Lyric vídeo; Desenho gráfico; Analises do discurso audiovisual; Tipografia cinética; Youtube; Fandom 


\section{Cómo citar el artículo}

Pérez Rufí, J. P. (2018). Lyric vídeos: el encuentro del videoclip con el diseño gráfico y la composición tipográfica [Lyric videos: the meeting of the music video with graphic design and the typographic composition]. Vivat Academia. Revista de comunicación, $\mathrm{n}^{\mathrm{o}}$ 144, 01-18. doi: http://doi.org/10.15178/va.2018.144.01-18 Recuperado de http:/ / www.vivatacademia.net/index.php/vivat/article/view/1071

\section{INTRODUCCIÓN}

Esta investigación tiene por objeto de estudio el lyric vídeo, un subgénero dentro del vídeo musical que, incluso si nacido con el éxito del propio formato televisivo promocional en los años ochenta, se desarrolla y se convierte en un contenido de amplia difusión en los últimos años, a partir de su consumo en la plataforma de contenidos de vídeo online YouTube y en su filial dedicada al videoclip, Vevo. YouTube se ha convertido en la vía prioritaria de distribución del videoclip, por encima incluso de la televisión especializada en contenidos musicales. La industria discográfica, principal productor del formato con un objetivo eminentemente comercial o promocional de contenidos musicales e intérpretes, ha adaptado la creación del videoclip a las nuevas condiciones de distribución y recepción, de tal manera que ha introducido importantes cambios en su configuración formal. Entre dichas adaptaciones del formato se encuentra el propio lyric vídeo, como videoclip que representa a través de códigos textuales íntegramente el contenido verbal de la canción, por lo general de manera sincronizada con aquella.

El uso del texto como un recurso activo en el discurso audiovisual ha estado presente en las producciones audiovisuales prácticamente desde el mismo inicio de la cinematografía (valgan como ejemplo las cartelas y rótulos del cine mudo, cuando no han sido filmados textos escritos en cualquier tipo de soporte). La televisión heredaría del cine el uso del texto, de un modo si cabe aún más funcional, a través de recursos fotográficos en primer lugar $\mathrm{y}$, posteriormente, de manera electrónica y digital. En el caso del videoclip, la representación del texto también es un recurso frecuente desde su mismo nacimiento, si bien su uso fue puntual o se utilizaba de manera recurrente para destacar palabras o líneas de texto de la canción, cuando no creaba un contraste o era el contrapunto del contenido de la canción, o era usado de un modo funcional (por ejemplo, para indicar el título de la canción o de los intérpretes).

Como subproducto relacionado con las industrias discográficas, los vídeos de karaoke se servían de la representación del texto junto a la ausencia del contenido vocal de la canción para invitar a sus aficionados a cantar dichos textos. Frente a este modelo de vídeo funcional, por cuanto servía de guía para interpretar el tema, el lyric vídeo se ha convertido en un formato de mayor creatividad y en una eficaz herramienta al servicio de los intereses promocionales y comerciales de la industria discográfica. Llamado en principio a satisfacer la demanda de los usuarios de contenidos sobre sus artistas favoritos y creados antes por los fans, más adelante serán las propias discográficas las que se impliquen activamente en su producción. El éxito del subgénero es tal que, en determinados casos, el lyric vídeo de un tema

Vivat Academia. Revista de Comunicación. 15 septiembre/15 diciembre, 2018, n 144, 01-18 
musical ha llegado a tener mayor número de visualizaciones en YouTube que la edición "oficial" del vídeo promocional del single. Originados en principio como productos de bajo presupuesto y rápida producción, los lyric vídeos son tomados cada vez más en serio y el interés que la industria discográfica deposita en él se traduce en piezas de un acabado técnico perfecto y de una gran creatividad, lo que lleva a una mayor aceptación y difusión.

El lyric vídeo puede ser así concebido como un formato idóneo para las estrategias de distribución multiplataforma que pretenden diversificar las vías de difusión de la producción de las discográficas y ampliar así con nuevas posibilidades sus estrategias de comunicación, dentro de planes de marketing cultural cada vez más amplios y ambiciosos. En el plano creativo, el lyric vídeo ha otorgado un mayor protagonismo al grafismo digital y a sus múltiples opciones, explotando la relación entre el Diseño gráfico y el vídeo musical. El necesario uso de las tipografías para la representación gráfica del texto escrito pone de relieve, por otra parte, la necesidad de un estudio, aún no abordado, de la relación entre el texto escrito y el discurso audiovisual.

Nuestra investigación pone en relación el vídeo musical con la aplicación de tipografías en el discurso audiovisual, relación que estudiaremos a través de un análisis de contenido, atendiendo a los recursos más frecuentes y a su variedad en una muestra de lyric videos. Aplicamos una metodología de análisis del discurso audiovisual adaptada especialmente al estudio del uso de códigos gráficos/textuales. La hipótesis de la que parte nuestro estudio es que los lyric vídeos hacen un uso frecuente de una serie de recursos formales al punto de que llegan a definir la naturaleza del formato como subgénero dentro del vídeo musical, recursos que a su vez permiten su categorización.

El lyric vídeo apenas ha sido estudiado previamente más allá de las páginas que le dedica Selva (2014) en su obra El videoclip. Comunicación comercial en la industria musical. Nos apoyaremos, en todo caso, en los estudios monográficos recientes dedicados al videoclip realizados por las investigadoras Vernallis (2013), RodríguezLópez (2016) o Sedeño (2012), junto a otros referentes como Viñuela (2008), Tarín Cañadas (2012) u O'Keeffe (2014). Recurrimos de igual modo a la metodología para el análisis discursivo y narrativo de Casetti y Di Chio (1991) en la relación entre los códigos gráficos y textuales y el discurso audiovisual y a la compilación de aportaciones al estudio de la composición tipográfica realizada por Williams (2015).

\section{OBJETIVOS}

Dada la ausencia de literatura académica publicada acerca del lyric vídeo, este trabajo se plantea dos objetivos básicos como primer acercamiento al formato:

-Analizar el formato definido como lyric vídeo con objeto de describir la actualización de recursos formales relacionados con la presencia de texto, tales como la relación entre la diégesis discursiva y el texto, el dinamismo de los textos, la variedad de familias tipográficas empleadas y la clasificación de dichas tipografías. Aunque no contabilizamos la frecuencia de actualización de estos recursos, dada la 
limitada muestra de la que partimos, sí tomamos nota de las posibilidades formales del formato.

-En un segundo paso, y conocida la naturaleza de las piezas analizadas, intentamos realizar una clasificación de los lyric vídeos en diferentes categorías a partir de las variables que han sido consideradas dentro de la metodología de análisis.

\section{NATURALEZA Y ORIGEN DEL LYRIC VÍDEO}

La complejidad de definición del lyric vídeo es paralela a la del propio videoclip, formato cada vez más extraño según Vernallis (2013, p. 181) y de una versatilidad tan amplia que evitaría el consenso en cuanto a los rasgos que darían unidad al conjunto de prácticas (Viñuela, 2008, p. 236). El concepto de videoclip dependerá de la perspectiva desde la que se estudie; así, si ponemos el acento en las cuestiones relativas a su producción, habremos de entenderlo como un producto cultural creado por la industria discográfica y ligado a un objetivo comercial o promocional; desde la óptica del análisis del discurso, sería un formato audiovisual de breve duración en el que la banda de imágenes quedaría subordinado a la banda de sonido, por lo general un tema musical, con multitud de posibilidades de realización y de edición y no obligado a seguir un desarrollo narrativo; en cuanto a creación audiovisual, supondría un fenómeno artístico de naturaleza audiovisual ligado a la experimentación formal y a la exploración de todas las posibilidades que las materias que lo conforman le permiten. Aceptamos como válida la acepción más general y formal de Tarín Cañadas (2012, p. 154), para quien el videoclip es una "creación audiovisual que construye un relato, en la interrelación de música e imagen, que se confiere como una obra única" y que tiene por objetivo por lo general la promoción de otros contenidos culturales, es decir, la canción. Otra definición muy completa la aporta Rodríguez-López (2016, p. 15), para quien el vídeo musical es “un producto audiovisual y promocional de la industria discográfica que toma influencias directas del lenguaje cinematográfico, publicitario y de las vanguardias artísticas", como traducción en códigos visuales de una canción mediante técnicas impactantes que pretenden forjar "una imagen de marca alrededor del cantante".

El lyric vídeo apenas ha sido objeto de atención por parte de la investigación en el videoclip. Entre los pocos autores que han abordado su estudio podemos citar a Selva, para quien el lyric vídeo sería un videoclip basado "en la reproducción visual de la letra íntegra de la canción” (Selva, 2014, p. 347). El mismo autor señala que la presencia del texto escrito en el vídeo musical no suele tener excesiva importancia, si bien también reconoce que el lyric vídeo es "un fenómeno que parece haber cobrado cierta importancia en los últimos años" (Selva, 2014, pp. 346-347).

Los orígenes del mismo no quedan demasiados claros. El referente previo (casi un proto-videoclip aún) podría constituirlo la secuencia del tema "Subterrean Homesick Blues", dentro del documental dedicado a Bob Dylan dirigido por D.A. Pennebaker Don't look back (1967), si bien la secuencia de carteles que Dylan va mostrando y dejando caer no recogen íntegramente el texto de la canción, por lo que no llega a ser un lyric vídeo. Este concepto ha sido después repetido por videoclips como "Mediate" de INXS (1987), "Like Dylan in the Movies" de Belle \& Sebastian (1996),

Vivat Academia. Revista de Comunicación. 15 septiembre/15 diciembre, 2018, n 144, 01-18 
"Jerusalem" de Steve Earle (2002) o "Salty Eyes" de The Matches (2006), e incluso por una secuencia de la película Ciudadano Bob Roberts (Bob Roberts, Tim Robbins, 1992).

Como primer antecedente del lyric vídeo, Selva menciona "Sign O'The Times" de Prince (1987) o "Praying for Time" de George Michael (1990) (Selva, 2014, p. 348). O’Keeffe (2014) atribuye la innovación al vídeo del grupo R.E.M. "Fall On Me" (1986), si bien tenemos que mencionar que la representación del texto escrito en pantalla fue un recurso muy habitual en los vídeos musicales de hip hop y rap en los años ochenta y, muy especialmente, en los primeros noventa. Hemos de apuntar, en todo caso, que estos textos no reproducían el contenido textual del contenido vocal al completo, sino varias palabras. En este sentido, los primeros 40 segundos del tema "I Got You Under My Skin" (1990) de Neneh Cherry, correspondientes al texto cantado como rap por la cantante sueca, son representativos. En el hip hop y el rap el mensaje del contenido vocal del tema suele tener el protagonismo, de ahí que el videoclip respete la fuerza de la palabra y la represente por escrito con cierta frecuencia.

En 2014 la cadena de televisión temática especializada en música MTV (propiedad del grupo de comunicación Viacom y con emisoras franquiciadas en multitud de mercados nacionales) creaba la categoría "Best Lyric Video" en sus premios anuales MTV Video Music Awards. Este hecho viene a ser la consecuencia del éxito del formato en los últimos años, como mencionaba Selva, y responde a la nueva realidad del consumo de contenidos audiovisuales musicales por parte de los usuarios de Internet y de los espectadores de MTV. Según O’Keeffe (2014), la apuesta de la industria discográfica por la producción de lyric vídeos nace del cambio en la normativa de medición del éxito de los singles en la lista estadounidense Billboard a principios de 2013, dado que a partir de ese momento se consideraría también como indicativo del éxito de un tema musical el número de reproducciones en plataformas de vídeo en streaming. Este hecho invitaba a las discográficas a tener contenidos creados por aquellas que explotar comercial y promocionalmente en portales como YouTube, antes incluso de la producción y distribución de videoclips "oficiales".

Lo cierto es que el fenómeno nace con el fan antes de que sean las discográficas las que produzcan los lyric vídeos. En un momento en el que no estar presentes en los principales canales de comunicación y distribución de contenidos entre los usuarios equivale a no existir mediáticamente, los usuarios creadores identificados con la figura del fan tienden a llenar los vacíos de contenidos "oficiales" de sus artistas favoritos con sus propias creaciones. El lyric vídeo se convierte así en un fenómeno surgido en YouTube antes que en Vevo, la filial del canal de vídeo de Google fruto de su acuerdo con las grandes multinacionales discográficas. Los usuarios demandan contenidos de artistas musicales en YouTube y lo crean cuando las discográficas no se lo ofrecen; dada la naturaleza audiovisual de la plataforma, los usuariosproductores no se limitarán a subir vídeos sin imágenes y con el único soporte de la pista de audio, sino que crearán fan-vídeos primero con imágenes fijas de los artistas (animadas o no en su edición) o de las portadas de los discos, después con escenas de vídeo procedentes de otras producciones, en lo que algunos autores denominan UMV (User Music Video) (Sedeño, 2012, p. 1231; Milstein, 2007, p. 31), y, finalmente, sirviéndose del propio texto de la canción para crear un formato que sirva para destacar el contenido textual. Con todo, la democratización en la creación y distribución de contenidos, apuntan Pérez Rufí y Gómez Pérez, es antes teórica que 
real, dado que "las clases se mantienen en el portal y los canales oficiales de grandes empresas se colocan por delante de los de usuarios" (Pérez Rufí y Gómez Pérez, 2013, p. 176). De esta forma, la industria discográfica termina por ocupar el espacio creado por el fan.

La flexibilidad de la industria discográfica, que aprendió finalmente a usar a su favor los medios online después de la traumática resistencia a la distribución de sus contenidos digitales a través de Internet, la llevó a adoptar el género auspiciado y promovido por los usuarios y a producir lyric vídeos y difundirlos antes de la publicación del vídeo oficial, caso de llegar a tenerlo, y de forma paralela a la edición del single o del álbum. El éxito de estos vídeos ha llevado a que, en varios casos, el número de reproducciones haya sido incluso superior a la de los vídeos oficiales, como es el caso de las piezas que se han seleccionado para su análisis en esta investigación. La industria discográfica ha ampliado la difusión de sus producciones mediante la aplicación de estrategias multiplataformas que incrementan las vías de distribución de sus contenidos y llenan de contenido aquellas plataformas en las que existe una demanda por parte de los usuarios. De esta forma, el lyric vídeo es promocionado como avance de contenidos audiovisuales posteriores (el videoclip "oficial") y como producción simultánea al mismo, llegando a rivalizar en aceptación y difusión pero beneficiando en todo caso siempre a la industria y a los creadores.

Como parte de esta estrategia de aumento de la producción controlada de contenidos ligados a un contenido musical, podemos encontrar nuevos formatos especializados de videoclips como el "dance vídeo" (vídeo musical basado en la interpretación de una coreografía del single promocionado, no necesariamente protagonizado por sus intérpretes), los "sneak peek" (o avances de varios segundos del vídeo o del audio del tema), los vídeos que sirven de soporte audiovisual a los remixes, versiones interpretadas en vivo o en un único escenario frente a la multitud de escenarios que en ocasiones se muestran en un videoclip o ediciones basadas en nuevas versiones del tema (valga como ejemplo el vídeo distribuido en YouTube/Vevo de Shakira "Chantaje (Versión Salsa)[Official Video] ft. Maluma"). A través de la explotación multiplataformas de sus productos, la industria discográfica incrementa la difusión dentro de su control y limita la ocupación de los espacios para su propagación que hacía el fan, cuyos contenidos serán cada vez de acceso más complejo a través de los buscadores de las plataformas de vídeo online, que premian y posicionan mejor aquellos contenidos con mayores visualizaciones, producidos y promocionados por la industria.

Desde el punto de vista de la creación, el lyric vídeo puede ser un contenido funcional, a diferencia del vídeo musical, desde el momento en que representa el texto de la canción por escrito e invita a atender al contenido vocal de la canción, a cantarla o a aprender la letra. Por otra parte, permite la aplicación de la identidad gráfica ligada a la producción y al intérprete, sirviendo de vehículo al servicio de una marca, en definitiva.

\section{METODOLOGÍA}

El vídeo musical es un formato audiovisual con multitud de opciones formales que liga sus resultados a la explotación de técnicas dependientes de la frecuente y 
pronunciada creatividad de sus creadores, donde la funcionalidad en el uso de la imagen no es obligada, al tiempo que la narratividad tampoco se perfila como un objetivo. Esta variedad de opciones y la aparente ausencia de aplicación de una gramática de la imagen explican la complejidad de su estudio académico y los frustrantes intentos de categorización. Desde el momento en que hemos decidido focalizar nuestra atención en una aplicación precisa del formato que se define desde el uso de sus opciones formales, nuestra investigación se articulará desde el análisis del discurso audiovisual y, dentro de éste, el análisis de contenido. Citando a Rodríguez-Lópéz (2014, p. 279), el vídeo musical se entiende "como un texto audiovisual susceptible de un análisis pormenorizado como tal y como acto de la comunicación visual", de tal modo que el análisis de contenido se centraría "en la codificación de propiedades observables en los textos".

Realizaremos un análisis textual del formato, según lo entienden Casetti y Di Chio (1991) en relación al filme: descompondremos las piezas presentes en la muestra y las recompondremos para así descubrir sus principios de construcción y su funcionamiento. Mediante el análisis de contenido pretendemos conocer los recursos más frecuentes en el lyric video y así identificar prácticas que definan su actualización formal.

La muestra que tomemos habrá de ser analizada conforme a una metodología coherente con la hipótesis y los objetivos de los que partimos y condicionará las conclusiones a las que lleguemos, como no puede ser de otra forma. La extensión de un artículo de investigación invita a tomar una muestra no muy abundante; consideramos que el análisis de diez videoclips puede permitirnos alcanzar conclusiones adecuadas a nuestros planteamientos. A la hora de decidir qué videoclip analizar, hemos intentado reducir condicionantes subjetivas y acudir a referentes más o menos objetivos que limiten la amplísima variedad de criterios que podrían considerarse en la elección. Así, hemos realizado la búsqueda de las piezas a través de YouTube: el portal propiedad de Google se caracteriza por una amplia variedad de contenidos y los acuerdos y la complicidad con la industria discográfica han hecho de ésta la plataforma actual más apropiada para la distribución de vídeos musicales y para su localización por parte de la audiencia. La búsqueda de los términos "lyric video" en el buscador del portal el 20 de febrero de 2017 dio lugar a "unos 70.200.000 resultados", según la plataforma. Sobre esta búsqueda aplicamos un filtro según la fecha de subida, eligiendo "este año" (es decir, durante los doce meses anteriores), resultando "unos 59.800 .000 resultados filtrados", y ordenamos los resultados por número de visualizaciones. Hemos elegido los diez con mayor número de reproducciones, descartando de los resultados dos piezas que en realidad eran "dance videos" (una modalidad de clip diferente).

Las razones de los criterios que han delimitado nuestra búsqueda han sido, por una parte, acotar la selección a casos recientes, a fin de que nuestro estudio ofrezca unos resultados ligados a la actualidad del formato; por otra parte, consideramos que la selección de las piezas con mayor número de reproducciones supone un criterio objetivo donde se imponen las preferencias de consumo de los usuarios de YouTube y la fuerza promocional de la industria musical. Tendremos así acceso a una muestra que reproduce los patrones de consumo masivo acumulado de contenidos 
audiovisuales en poco tiempo propios de los éxitos musicales y que entendemos que da lugar a un conjunto representativo de piezas que analizamos.

Los lyric vídeos analizados son los siguientes:

-The Chainsmokers - Closer (Lyric) ft. Halsey

-Major Lazer - Cold Water (feat. Justin Bieber \& MØ) (Official Lyric Video)

-DJ Snake ft. Justin Bieber - Let Me Love You [Lyric Video]

-Ed Sheeran - Shape Of You [Official Lyric Video]

-Enrique Iglesias - Duele el corazon (Lyric Video) ft. Wisin

-Ed Sheeran - Castle On The Hill [Official Lyric Video]

-The Chainsmokers - Paris (Lyric)

-Phía Sau Một Cô Gái - Soobin Hoàng Sơn (Official Lyric Video)

-La Rompe Corazones - Daddy Yankee Ft Ozuna (Lyric Video)

-MC Hariel e MC Pedrinho - 4M No Toque (Lyric Vídeo) Jorgin Deejhay

Como parte de la metodología de análisis del discurso que aplicamos en cada vídeo, tomamos en primer lugar nota de la naturaleza de la imagen de la pieza audiovisual. En este sentido, distinguimos entre los vídeos con un soporte de imagen filmada, una obra de completa creación a través de recursos de grafismo digital (sin imagen real filmada, por tanto), o mezclando ambas fuentes de imágenes. Frecuentemente, los lyric videos son publicados con antelación a la publicación de los singles o de los vídeos oficiales y no siempre se cuenta con grabaciones audiovisuales, siendo una pieza editada con imágenes y recursos enteramente digitales.

En segundo lugar, atendemos a la forma de integración de los textos dentro de la pieza. Siguiendo la distinción de Casetti y Di Chio (1991, p. 97), identificamos si los textos son diegéticos o extradiegéticos. Los textos diegéticos son aquellos que pertenecen al plano de la historia, es decir, aquellos que han sido filmados como elemento integrado dentro de la puesta en escena; los textos no diegéticos (o extradiegéticos) serían aquellos "extraños al mundo narrado, aunque formando parte del mundo de quien narra", o sea, los textos que no pertenecen a la puesta en escena y son incorporados en la edición de la pieza de manera fotográfica, electrónica o digital.

En el tercer punto de nuestro esquema de análisis centramos nuestra atención en una cuestión precisa de la edición de los textos presentes en el discurso, el movimiento o no de los mismos. Queremos así conocer si aplicarían las técnicas de tipografía cinética (kinetics typography); según la revista Graffica (2016), la tipografía cinética es la técnica de animación de textos que tiene "la finalidad de transmitir y expresar emociones a través del movimiento de éste", por lo general a través de programas de edición como Adobe After Effects. La animación de textos, añadimos, dificultaría la legibilidad de los mismos pero crearía un impacto adicional sobre su propia presencia en el discurso, gracias a su mayor focalización y consecuente protagonismo.

Siguiendo con cuestiones más ligadas a la tipografía, en cuarto lugar contabilizamos el número de tipografías utilizadas en el clip para señalar si usa una 
sola, si aparecen dos o tres o si son más de tres. Es una norma común en los manuales para diseñadores gráficos que el número de tipografías de una composición debe ser muy pequeña, dado que podría hacer el mensaje más confuso (Williams, 2015). La cuestión en este caso sería saber si la creatividad artística del videoclip justificaría pasar por alto las cuestiones de diseño más ligadas a la eficacia comunicativa de las composiciones o no.

En quinto y último lugar, en línea con el anterior análisis del uso de las tipografías, las clasificamos para intentar descubrir tendencias al respecto, incluso si nuestra muestra es muy limitada. Son muchas las clasificaciones de familias tipográficas, desde las de Francis Thibodeau (1921), Maximilien Vox (1954) o Aldo Navarese (1958), hasta las de asociaciones como la Association Typographique Internationale (1962) o la British Standards Institution (1965). Partiremos en nuestro caso, por su simplicidad y facilidad en el reconocimiento de los tipos, de la propuesta de Robin Williams (2015) a partir de la combinación y simplificación de las anteriores clasificaciones. Williams distingue seis categorías: Oldstyle (tipografías con serifa con remates en ángulo, transición grueso/fino moderado y distribución de partes más finas o acento diagonal), Modern (tipografías con serifa con remate horizontal delgado, transición grueso/fino radical y acento vertical), Slab Serif (tipografías con serifa con remate horizontal grueso, sin apenas transición grueso/fino y acento vertical), Sans Serif (tipografías sin serifa), Script (tipografías que imitan la escritura manual a través de cualquier instrumento) y Decorativas (todas las demás fuentes que no siguen los parámetros de las categorías anteriores).

\section{RESULTADOS Y DISCUSIÓN}

Representamos en primer lugar una tabla en la que se recogen los resultados de la aplicación de la metodología elegida en la muestra seleccionada para su análisis.

\begin{tabular}{|c|c|c|c|c|c|c|c|c|c|c|c|c|}
\hline \multirow[t]{2}{*}{ Vídeo } & \multicolumn{3}{|c|}{ Imagen } & \multicolumn{3}{|c|}{$\begin{array}{l}\text { Texto } \\
\text { diegético/extradiegético }\end{array}$} & \multicolumn{2}{|c|}{$\begin{array}{l}\text { Tipogr. } \\
\text { Cinética }\end{array}$} & \multicolumn{3}{|c|}{$\begin{array}{l}\text { Tipografías: } \\
\text { cantidad }\end{array}$} & \multirow[t]{2}{*}{$\begin{array}{l}\text { Categoría } \\
\text { tipográfica }\end{array}$} \\
\hline & Film & Graf & Mix & Dieg & Extra & Mix & Sí & No & 1 & $2-3$ & +3 & \\
\hline $\begin{array}{l}\text { The Chainsmokers - } \\
\text { Closer (Lyric) ft. } \\
\text { Halsey }\end{array}$ & $X$ & & & & $\mathrm{X}^{*}$ & $\mathrm{X}^{*}$ & $X$ & & & $X$ & & Script \\
\hline $\begin{array}{l}\text { Major Lazer - Cold } \\
\text { Water (feat. Justin } \\
\text { Bieber \& MØ) (Official } \\
\text { Lyric Video) } \\
\end{array}$ & & $X$ & & & $X$ & & $X$ & & & & $X$ & $\begin{array}{l}\text { Decorativa } \\
\text { Script } \\
\text { Sans serif }\end{array}$ \\
\hline $\begin{array}{l}\text { DJ Snake ft. Justin } \\
\text { Bieber - Let Me Love } \\
\text { You [Lyric Video] }\end{array}$ & & $\bar{X}$ & & & $\bar{X}$ & & $X$ & & $X$ & & & Decorativa \\
\hline $\begin{array}{l}\text { Ed Sheeran - Shape Of } \\
\text { You [Official Lyric } \\
\text { Video] }\end{array}$ & & $X$ & & & $X$ & & $x$ & & & & $X$ & Todas \\
\hline $\begin{array}{l}\text { Enrique Iglesias - } \\
\text { DUELE EL } \\
\text { CORAZON (Lyric } \\
\text { Video) ft. Wisin }\end{array}$ & & $x$ & & & $X$ & & $x$ & & $x$ & & & Sans serif \\
\hline $\begin{array}{l}\text { Ed Sheeran - Castle } \\
\text { On The Hill [Official } \\
\text { Lyric Video] }\end{array}$ & & $X$ & & & $X$ & & $X$ & & $X$ & & & Script \\
\hline $\begin{array}{l}\text { The Chainsmokers - } \\
\text { Paris (Lyric) }\end{array}$ & $X$ & & & & $X$ & & $X$ & & & $X$ & & Script \\
\hline PHÍA SAU MỘT CÔ & & $\mathrm{X}$ & & & $X$ & & & $X$ & & $X$ & & Sans serif \\
\hline
\end{tabular}




\begin{tabular}{|l|l|l|l|l|l|l|l|l|l|l|l|l|}
\hline $\begin{array}{l}\text { GÁI - Soobin Hoàng } \\
\text { Son ( OFFICIAL Lyric } \\
\text { Video ) }\end{array}$ & & & & & & & & & & & & \\
\hline $\begin{array}{l}\text { La Rompe Corazones - } \\
\text { Daddy Yankee Ft } \\
\text { Ozuna (Lyric Video) }\end{array}$ & & $X$ & & & $X$ & & $X$ & & & & X & $\begin{array}{l}\text { Sans serif } \\
\text { Decorativa } \\
\text { Script }\end{array}$ \\
\hline $\begin{array}{l}\text { MC Hariel e MC } \\
\text { Pedrinho - 4M No } \\
\text { Toque (Lyric Vídeo) } \\
\text { Jorgin Deejhay }\end{array}$ & X & & & & $X$ & & $X$ & & $X$ & & & Sans serif \\
\hline
\end{tabular}

Figura 1: Análisis de la muestra seleccionada de lyric vídeos (2016-2017).

Fuente: Elaboración propia, a partir de YouTube.

El estudio de cuestiones relacionadas con los aspectos formales del lyric vídeo, dentro del análisis de contenido permite obtener resultados interesantes acerca de la construcción del vídeo y llegar a conclusiones que podrían apuntar a una posible modelización del formato.

Haremos, en primer lugar, algunos comentarios acerca de la muestra tomada para el análisis. Ignoramos cuál es el algoritmo que permite al buscador de YouTube acceder a los resultados que propone, pero puede ser resultar relevante que a la hora de introducir un filtro de tiempo (vídeos subidos en los últimos doce meses) se obtenga sólo un 15\% menos de resultados (59.800.000 vídeos en lugar de 70.200.000). De responder al total de contenidos almacenados en la plataforma, esto significaría que el $85 \%$ de los vídeos clasificados como lyric vídeos dispuestos en la plataforma habrían sido distribuidos en el último año. Este hecho bien podría significar o que el lyric vídeo se ha convertido en un formato de gran presencia y relevancia a lo largo de 2016, o bien que la catalogación e indexación del formato como lyric vídeo ha tomado mayor prestancia en el último año.

Con respecto a los diez vídeos seleccionados, comprobamos que pese al predominio de los contenidos creados por las grandes discográficas multinacionales que se imponen con la elección mayoritaria de los usuarios, hay lugar también para la diversidad, al menos idiomática y de procedencia de la producción: seis de los vídeos son canciones en inglés, dos son en castellano, uno es en portugués de Brasil y otro es en vietnamita. Recordemos que estos vídeos son los lyric vídeos que concentran mayor número de reproducciones, por lo que la elección de la muestra ha priorizado la popularidad y el consumo masivo mundial de determinados contenidos. Como dato interesante pero no determinante en cuanto al objetivo de nuestro estudio, apuntemos que el número de reproducciones en YouTube de la muestra fue de las 1.184 millones de visualizaciones de "Closer" a las 72 millones de "4M No Toque".

Entrando ya en el análisis discursivo, señalaremos en primer lugar que hemos contabilizado en menor número de ocasiones lyric vídeos que tienen como soporte visual imágenes filmadas (sólo en tres vídeos). Nuestro propósito no es cuantificar los resultados ni llegar a conclusiones estadísticas acerca de la frecuencia de determinadas prácticas, pero este dato resulta significativo. Así, la práctica más frecuente es su generación a través de recursos digitales (grafismo digital) en el que no es necesaria la puesta en marcha de una producción audiovisual tradicional, donde se parte del registro de una escena con actores, escenarios y el resto de componentes de la puesta en escena cinematográfica clásica. Podríamos así afirmar 
que el lyric vídeo nace como formato audiovisual de naturaleza eminentemente digital a partir del uso de herramientas informáticas de diseño gráfico o audiovisual, siendo el resultado de un trabajo de edición antes que de producción fílmica.

De los tres casos de vídeo con imagen filmada que encontramos, dos pertenecerían al grupo The Chainsmokers y son bastantes similares en su concepto: en "Closer" vemos las imágenes de una pareja en vacaciones por la playa y diversos escenarios, sin interpretar el tema musical, y en "Paris" es una chica la que pasea por la playa, sin mayores elementos narrativos ni de interpretación de la canción. En el tercero de los vídeos, los jóvenes cantantes del tema musical interpretan la canción mirando a cámara y bailando en un escenario neutro, como clip puramente "performativo".

Aunque tampoco es nuestro objetivo realizar una valoración crítica de los contenidos, advertimos que la calidad de estas producciones audiovisuales filmadas tampoco es demasiada, más allá del cuidado técnico en la filmación y la edición. La producción parece ser así muy económica, sin grandes medios ni un desarrollo creativo o formal que los distancie de clips de bajo presupuesto más mediocres.

En cuanto a los lyric videos generados mediante grafismo digital, advertimos una gran variedad de posibilidades, que van desde las piezas de animación más creativas para los dos singles de Ed Sheeran a los más convencionales clips de Enrique Iglesias o de Phía Sau Một Cô Gái, prácticamente vídeos de karaoke con la letra de la canción sobre fotografías del intérprete. Los vídeos más elaborados se convierten así casi en cortos de animación en los que el texto tiene una focalización prioritaria. Entendido así, el formato se presta con mayor eficacia a intentar transmitir el tono y los valores asociados tanto a la canción como a la identidad creada para el intérprete o para un proyecto musical concreto. Los vídeos generados por grafismo digital crean su propia diégesis de mundos posibles o de articulación de recursos formales con independencia absoluta de los referentes reales, lo que permite una gran variedad de posibilidades al servicio de las voluntades artísticas de los creadores.

El siguiente aspecto del análisis atiende a la presencia de textos de manera diegética o extradiegética. Existe en la muestra tomada unanimidad: todos los textos sería extradiegéticos, es decir, no pertenecientes a la puesta en escena o a la imagen filmada al ser agregados (digitalmente) mediante programas de edición. Aunque no es aquí el caso, pueden localizarse vídeos en los que los textos han sido integrados dentro del escenario y los cambios de encuadres o de plano han explorado y "leído" dichos textos.

La razón por la que los textos son extradiegéticos puede deberse a una mera cuestión de producción y de economía de los medios: la integración de los textos en la imagen filmada exigiría una planificación muy precisa y en muchas ocasiones prácticamente una articulación detallada a modo de coreografía de todos los componentes de la puesta en escena. Sin embargo, la edición de los textos en la fase de postproducción permite una menor dependencia de la filmación previa. Lyric vídeos muy cuidados como el de Ed Sheeran "Shape of You" requerirían de la misma planificación precisa y coreográfica de los vídeos filmados con textos diegéticos, si bien formarían siempre parte del proceso de postproducción, con la flexibilidad que permiten los programas de edición de vídeo y postproducción digital.

Apuntemos, dentro de la muestra tomada, como única excepción la presencia de dos planos con textos diegéticos en el vídeo de The Chainsmokers "Closer", donde el 
nombre de los intérpretes y de la canción aparecen escritos al pie de unas fotografías tomadas con Polaroid. El resto del clip incorpora los textos de manera extradiegética, razón por la que hemos clasificado el modo de incorporación de los textos en dicha categoría.

Con respecto a la cinética de las tipografías, observamos que la práctica totalidad de los lyric vídeos de la muestra (a excepción del vídeo del intérprete vietnamita) editan los textos (extradiegéticos) en movimiento. De esta manera se consigue un impacto adicional sobre los mismos, ganando en focalización y protagonismo, al tiempo que se imprime sobre el formato un efecto de ritmo y de dinamismo, de velocidad. La creación de una impresión de ritmo no se consigue, por tanto, únicamente a través de una edición acelerada de planos de corta duración en su desarrollo temporal, sino también con el movimiento de los textos dentro de cada plano o dentro de los encuadres.

Como consecuencia, los textos dificultan su legibilidad. Este hecho definirá un rasgo básico de la naturaleza del lyric vídeo: frente a la funcionalidad del vídeo de karaoke, en el que la aparición de los textos queda subordinada a la optimización de la lectura en las mejores condiciones, el lyric vídeo juega con los textos como un recurso antes artístico (incluso estético) que funcional, razón por la que una mejor legibilidad no es el objetivo a lograr.

La cantidad de familias tipográficas presentes en cada uno de los vídeos analizados es una cuestión más relacionada con la composición tipográfica y el diseño gráfico que propiamente el análisis del discurso audiovisual. Sin embargo, al tratarse el texto del recurso preferente del lyric vídeo, consideramos que su inclusión en este estudio permite llegar a conclusiones acerca de la naturaleza y el uso del lenguaje audiovisual del formato analizado.

En este apartado observamos que el número de familias aplicadas en los textos de cada vídeo no sigue tendencias comunes y se recurre a todo tipo de opciones. Así, en cuatro piezas de la muestra seleccionada se usa una sola tipografía. Los manuales para diseñadores gráficos suelen recomendar, como hemos apuntado, la simplificación de la cantidad de recursos gráficos y tipográficos (Williams, 2015), lo que llevaría a la reducción del número de tipografías de la composición de una imagen fija. De esta manera, se reduciría la complejidad de la composición, se limitaría la creación de significados que resultaría de la mezcla tipográfica y de los valores de cada una de las tipografías y se pondría el acento en la funcionalidad de la composición y en la optimización de la legibilidad de los textos.

En el caso del lyric vídeo con una sola familia tipográfica, se resta atención sobre la fuente (entendida como un elemento gráfico, al tratarse de una figura sobre un fondo) para intentar desplazar el interés del lector hacia otros elementos de la pieza audiovisual: el contenido de los textos, su composición, otro tipo de recursos, el contenido de la puesta en escena, el componente sonoro, etc. Los cuatro vídeos que aplican sobre sus textos una sola familia tipográfica son muy dispares en el resto de contenidos y recursos presentes (incluyendo aquí las piezas de animación con textos de Dj Snake ft Justin Bieber o Ed Sheeran en "Castle On The Hill", así como el vídeo más simple de MC Hariel e MC Pedrinho o el clip prácticamente de karaoke de Enrique Iglesias), lo que no nos permite llegar a conclusiones que unifique el sentido del uso de una sola tipografía más allá de las razones señaladas. 
Tres serán los lyric vídeos de la muestra que apliquen dos o tres familias tipográficas y otros tres los que presenten más de tres familias. El objetivo de la variedad tipográfica vendría ligado a las intenciones artísticas y de dinamismo del formato: al margen de la funcionalidad que impone la limitación de familias, el lyric vídeo pretende mantener la atención haciendo uso de todos los recursos de los que dispone, incluyendo tanto la tipografía cinética como la diversidad de fuentes, estilos, colores, etc. Llamemos la atención sobre el uso particular que se hace del número de familias en el lyric vídeo de The Chainsmokers "Closer"; en este caso los textos se representarían con dos familias tipográficas distintas, una para el texto cantado en la pista sonora por el intérprete masculino y otra para el texto cantado por la intérprete femenina. Se hace de esta manera un uso funcional de la elección tipográfica.

Acerca de las categorías más frecuentes en la muestra tomada, destacan por encima de todas los tipos script, es decir, aquellas fuentes que simulan haber sido escritas a mano. Las tipografías script aparecen en seis de los diez vídeos analizados. Podríamos interpretar que su uso responde a la necesidad de transmitir los valores asociados a su aparente naturaleza humana: aquí el intérprete parece escribir de su propio puño los textos, transmitiendo una impresión de contenido más humano y cercano, frente a la frialdad y normalización de las tipografías creadas "a través de la máquina".

En el caso de los textos de "Closer" de The Chainsmokers esta identificación entre tipografía manuscrita e intérpretes se refuerza desde el momento en que los tipos son dos, en función de si el texto cantado es interpretado por el cantante o por la cantante del tema. Los textos de "Castle On The Hill" de Ed Sheeran también parecen responder a esta voluntad del cantautor de narrar sus propias experiencias vitales, desde el momento en que la canción simula hacer un relato biográfico de diferentes etapas de su vida.

El uso de la categoría script podría así ligarse a la voluntad de personalización no sólo de los textos, sino también del tema musical y del videoclip. Otra interpretación podría desprenderse de este uso mayoritario de las tipografías script: la segunda década del siglo XXI ha visto muy potenciado el uso de las script hasta convertirse en un fenómeno de moda. Si previamente los manuales de Diseño gráfico no recomendaban su uso debido a la dificultad de legibilidad que podían presentar y a la informalidad que connotaban, incluso infantilismo (Williams, 2015), en los últimos años pasan a ser un recurso habitual en composiciones ligadas a una estética moderna y en principio minoritaria: la estética hipster vino ligada a la nostalgia, al gusto por lo retro y lo vintage, como se pudo percibir a partir de la reivindicación de los materiales antiguos, los productos industriales y artesanales desgastados, las solerías de azulejos hidráulicos, el uso de la pizarra y la tiza como soporte de mensajes informativos y publicitarios, el interés por la recuperación de la tecnología analógica desde un plano antes estético que funcional y todo lo que fuera sinónimo de artesanía o hecho a mano. Las tipografías script se prestaron a este uso nostálgico de formatos y técnicas de creación superadas de lejos por la digitalización de los medios de producción, y se convirtieron en el texto de moda, primero en contextos sociales más minoritarios y exclusivos y después más masivos, industriales y comerciales. Las tipografías script están de moda y los lyric vídeos se han 
subordinado a las tendencias de moda en composición tipográfica y visual, en definitiva.

En cinco de los vídeos analizados encontraremos tipografías sans serif, textos desprovistos de remates y austeros, neutros, fríos y tremendamente funcionales. Los tipos sans serif están, simultáneamente, tan desprovistos de elementos connotativos que expanden su universo ideológico, potenciando los valores del resto de recursos y contenidos de la composición. La neutralidad de las sans serif la convierte así en "esponjas" que se impregnan del mensaje transmitido por el contenido de la canción, por la identidad del artista o por el resto de recursos presentes en el discurso. Los vídeos de Phía Sau Một Cô Gái o Enrique Iglesias son tremendamente funcionales en este sentido e intentan eliminar casi toda la emoción en el uso de los textos. En el caso del lyric vídeo de Enrique Iglesias, dicha emoción o la connotación transmitida por el texto no procederá de la categoría tipográfica, sino de la mezcla de tamaños en las fuentes, su composición, alineaciones e incluso color, destacando de este modo algunas palabras por encima de otras. El clip de MC Hariel y MC Pedrinho no pretende tampoco llamar la atención sobre la figura del texto, sino sobre los propios intérpretes y el contenido de su mensaje, incluso si la tipografía es cinética y adquiere gran dinamismo en su modo de aparición y en la composición tipográfica general. El uso de las categorías tipográficas se remite así al que comentábamos como propio de los videoclips de rap y hip hop de los años noventa.

La creatividad y la aplicación de infinidad de recursos audiovisuales aceptados para el videoclip explicarían el uso de las tipografías denominadas por Williams decorativas. Éstas, más difícil de catalogar, responderán a las connotaciones de las que se quiere imprimir el texto escrito y al capricho de los creadores en su composición visual. Aparecerán en cinco de los vídeos analizados, en la mayoría de los casos combinadas con otras categorías (como las script o las sans serif). Como caso paradigmático, el lyric vídeo de "Shape of You" de Ed Sheeran presenta una pieza de animación gráfica en la que las posibilidades creativas del texto como recurso visual se explotan al máximo, incorporando multitud de fuentes (de todas las categorías), la variedad de colores, formas, disposición dentro del encuadre, etc. Se consigue así un enorme dinamismo y un resultado poco funcional en cuanto a la legibilidad del texto, pero atractivo, singular y con una vocación de búsqueda del valor artístico y de activación de estrategias de seducción visual.

A partir del análisis del discurso realizado sobre los lyric vídeos seleccionados nos atrevemos a modelizar las posibilidades que permite el formato y a establecer de esta manera tres categorías:

1) Lyric vídeo basado en la filmación o en la fotografía de escenas, en la que los textos pueden aparecer de manera diegética o extradiegética, con movimiento o no. En este tipo de vídeos suele limitarse el número de fuentes tipográficas y se comparte la focalización del contenido de la puesta en escena con el propio texto con la letra de la canción.

2) Lyric vídeo editado íntegramente de manera digital, sin presencia de una puesta en escena real que haya sido filmada o fotografiada. Basada en técnicas de edición de post-producción, suele focalizar su atención en los propios textos antes que en otros contenidos, lo que invita a explorar y explotar todas las posibilidades formales y 
discursivas que permite la edición digital, primando así lo artístico sobre lo funcional.

3) Lyric vídeo funcional. Más próximo al tradicional vídeo de karaoke, subordina la aplicación de efectos de realización o post-producción a la representación del contenido textual de la canción de la manera más eficaz y clara posible. El objetivo será la optimización de la legibilidad de los textos, lo que conducirá a textos estáticos o con limitadísimos efectos de movimiento y la reducción de la diversidad de fuentes tipográficas a una o dos familias que permitan una buena legibilidad.

4) El lyric vídeo mixto. Dada la amplia combinación de posibilidades que permite tanto el videoclip en general como el lyric vídeo en particular, creemos conveniente recurrir a una categoría más amplia y menos precisa donde cupieran todas aquellas prácticas que no llegaran a identificarse con las categorías mencionadas. Las posibilidades discursivas del lyric vídeo son muchas y sólo quedan limitadas por las constantes que definen su naturaleza como producto audiovisual al servicio de un tema musical en el que se representan gráficamente los textos que conforman el contenido vocal de la canción. El lyric vídeo mixto podría resultar igualmente de la combinación de los anteriores modelos categorizados.

\section{CONCLUSIONES}

La relativa novedad del lyric vídeo como fenómeno de gran demanda y amplio consumo reciente y la ausencia de una literatura académica que haya abordado previamente su investigación ponen de relieve la necesidad de consideración del formato dentro de la investigación del videoclip. El relativo bajo coste de producción que con frecuencia requiere y la posibilidad de obtener una difusión y un consumo multitudinarios a través de plataformas de vídeo online como YouTube lo convierte en un formato eficaz dentro de las estrategias de comunicación de las industrias discográficas. Si además consideramos que la suma de reproducciones de un producto musical en cualquier formato, medio y dispositivo contribuye a dar una mayor visibilidad a aquel y aumenta su notoriedad (como evidencian las normas que configuran la lista de éxitos Billboard), hemos de concluir que es un instrumento altamente funcional a los objetivos comerciales de la industria.

Considerado aún como formato previo al vídeo "oficial" en torno a un tema musical, cuando no complementario, hemos de apuntar que puede llegar a convertirse en un formato sustituto del anterior, al punto de que puede superar al vídeo "oficial" en cuanto a número de reproducciones en YouTube, caso de los lyricvídeos de muy bajo presupuesto de The Chainsmokers.

Como formato subsidiario del videoclip convencional, el lyric vídeo comparte con el vídeo musical su complejidad formal, justificada desde su carácter artístico y experimental y en la necesidad de mantener la atención del espectador y lograr impactarle o seducirle. De forma paralela, comparte con el videoclip la disparidad de posibilidades formales que puede actualizar y la consecuente dificultad de su análisis y categorización.

En todo caso, la necesidad obligada por la propia definición de la naturaleza del formato de representar los textos escritos dotará de unos recursos susceptibles de ser analizados y, con ello, de aplicar una metodología con categorías ante las que tendrán 
que posicionarse en un sentido $u$ otro cada uno de los lyric vídeos, pero que terminarán por configurar prácticas comunes e incluso frecuentes. En este sentido, hemos comprobado que el lyric vídeo ha vinculado como no lo hacían otros tipos de videoclips los fundamentos del Diseño gráfico con el discurso audiovisual, desde el momento en que el uso de las tipografías supone el soporte gráfico necesario para representarse por escrito los textos.

La principal conclusión a la que llega nuestro análisis es que la concepción del lyric vídeo implicará dos opciones diferentes ligadas a la funcionalidad de la composición y de la aplicación de recursos gráficos o textuales: así, encontramos piezas en las que el principal objetivo es transmitir el mensaje textual de la forma más eficaz, lo que explica composiciones más neutras, funcionales y ordenadas, propias del funcionalismo del Diseño suizo, frente a otro modelo de lyric vídeo en el que el objetivo no es la comunicación más eficaz del mensaje textual, sino la aplicación de técnicas creativas y artísticas en las que el texto es un recurso gráfico más, donde no primará consecuentemente la optimización de su legibilidad. Como en el videoclip, las opciones formales son tantas como quieran aplicar los creadores y sus opciones de estudio abren tantas vías de investigación como las abiertas por el propio vídeo musical.

\section{REFERENCIAS}

Casetti, F. \& Di Chio, F. (1991). Cómo analizar un film. Barcelona: Paidós. Graffica (2016). ¿Qué es la tipografía cinética?, Graffica. Recuperado de http:/ / graffica.info/que-es-la-tipografia-cinetica

Milstein (2007). Case Study: Anime Music Videos, En J. Sexton, (Ed.). Music, Sound and Multimedia: From the Live to the Virtual. Edimburg: Edimburg University Press.

O'Keeffe (2014). Where Did All These Videos Come From, and Why Are We Giving Them Awards?, The Atlantic. Recuperado de: https://www.theatlantic.com/entertainment/archive/2014/08/where-did-allthese-lyric-videos-come-from-and-why-are-we-giving-them-awards/376084/

Pérez Rufí, J.P. \& Gómez Pérez, F.J. (2013). Nuevos formatos audiovisuales en Internet: cuando el usuario es quien innova, en M. I. De Salas Nestares y E. Mira Pastor, (coord.). Prospectivas y tendencias para la comunicación en el siglo XXI. Madrid: CEU Ediciones.

Rodríguez-López, J. (2014). Diseño de un modelo crítico-estilístico para el análisis de la producción videográfica musical de Andy Warhol como industria cultural. (Tesis inédita de doctorado). Universidad de Huelva, Huelva.

Rodríguez-López, J. (2016). Andy Warhol y el vídeo musical. Huelva: Pábilo Editorial.

Sedeño, A. (2012). Producción social de videoclips. Fenómeno fandom y vídeo musical en crisis. Comunicación: revista Internacional de Comunicación Audiovisual, Publicidad y Estudios Culturales, 10, 1224-1235. Recuperado de https: / / dialnet.unirioja.es / servlet/articulo?codigo $=3992540 \&$ orden $=354871$ \&in fo=link.

Selva Ruiz, D. (2014). El videoclip. Comunicación comercial en la industria musical. Sevilla: Ediciones Alfar.

Vivat Academia. Revista de Comunicación. 15 septiembre/ 15 diciembre, 2018, nº 144, 01-18 
Tarín Cañadas, M. (2012). La narrativa en el videoclip Knives Out, de Michel Gondry. Icono 14, 10(2), 148-167. Recuperado de http://www.icono14.net/ojs/index.php/icono14/article/view/482/365

Vernallis, C. (2013). Unruly Media. YouTube, Music Video, and the New Digital Cinema. Oxford: Oxford University Press.

Viñuela Suárez, E. (2008). La autoría en el vídeo musical: signo de identidad y estrategia comercial. Revista Garoza, 8, 235-247. Recuperado de http://webs.ono.com/garoza/G8-Vinuela.pdf

Williams, R. (2015) Diseño gráfico: principios y tipografía. Madrid: Anaya Multimedia.

\section{AUTOR}

\section{José Patricio Pérez Rufí}

Profesor del Departamento de Comunicación Audiovisual y Publicidad de la Facultad de Ciencias de la Comunicación de la Universidad de Málaga. Es Doctor en Comunicación Audiovisual por la Universidad de Sevilla (2005), licenciado en Comunicación Audiovisual (1999) y licenciado en Periodismo (1997) por la Universidad de Sevilla. Es miembro del Equipo de investigación Communicav. Ha publicado diversas monografías en editoriales como T\&B, Síntesis, Quiasmo, Gerüst Creaciones, Tutorial Formación y Eumed.net. Ha participado en libros colectivos editados por T\&B, Dolmen, Fragua, Ministerio de Cultura e ICAA, Padilla o Edipo, entre otros. Ha publicado en numerosas revistas de investigación especializadas en Comunicación.

https://orcid.org/0000-0002-7084-3279

https://scholar.google.com/citations?user=Qf8yHP0AAAAJ 